\title{
Variation of the East Asian Monsoon and the tropospheric biennial oscillation
}

\author{
LI Chong Yin ${ }^{1,2^{*}}$, PAN Jing ${ }^{1} \&$ QUE ZhiPing ${ }^{1,3}$ \\ ${ }^{1}$ State Key Laboratory of Numerical Modeling for Atmospheric Sciences and Geophysical Fluid Dynamics, Institute of Atmospheric Physics, \\ Chinese Academy of Sciences, Beijing 100029, China; \\ ${ }^{2}$ Meteorological College, PLA University of Science and Technology, Nanjing 211101, China; \\ ${ }^{3}$ Graduate University of Chinese Academy of Sciences, Beijing 100049, China
}

Received April 16, 2010; accepted July 13, 2010

\begin{abstract}
Study of the tropospheric biennial oscillation (TBO) has attracted significant interest since the 1980s. However, the mechanism that drives this process is still unclear. In the present study, ECMWF daily data were applied to evaluate variation of the East Asian monsoon and its relationship to the TBO. First, the general East Asian monsoon index (EAMI) was delineated on the basis of a selected area using the $850 \mathrm{hPa} u$ and $v$ components. This new index may describe not only the characteristics of summer monsoons, but also the features of winter monsoons, which is crucial to understand the transition process between summer and winter monsoons. The following analysis of EAMI shows that there is a close relationship between summer and winter monsoons. In general, strong East Asian winter monsoons are followed by strong East Asian summer monsoons, and weak winter monsoons lead to weak summer monsoons. While strong (weak) summer monsoons followed by weak (strong) winter monsoons form a kind of 2-year cycle, which may be the possible mechanism leading to the TBO over the East Asian region.
\end{abstract}

East Asian monsoons, annual variation, interaction, tropospheric biennial oscillation (TBO), dynamical mechanism

Citation: $\quad$ Li C Y, Pan J, Que Z P. Variation of the East Asian Monsoon and the tropospheric biennial oscillation. Chinese Sci Bull, 2011, 56: 70-75, doi: 10.1007/s11434-010-4200-6

The East Asian monsoon system is the strongest and most active monsoon system in the region. It has two important components - the winter and summer monsoon. Both of these components impose important impacts on East Asia, global atmospheric circulation and climate. Thus, research on the East Asian monsoon system is of general importance [1-3]. While most previous studies have investigated winter or summer monsoons, some have tried to evaluate their interactions in East Asia. However, the specific nature of this relationship is still unclear. Through representative case analyses, Sun et al. [4,5] pointed out that the summer monsoon following a strong (weak) winter monsoon year tended to be weak (strong). Zhao et al. [6] found that there was an "out of phase" pattern between winter and summer in most years, and Chen et al. [7] suggested a winter monsoon index

*Corresponding author (email: lcy@lasg.iap.ac.cn) relative to a West Pacific subtropical high pressure (WPSH). These authors also indicated that the WPSH shifted northward (southward) in the summer after a strong (weak) winter monsoon year in East Asia. In addition, a relationship between East Asian monsoons and the precipitation over the Yangtze River valley area in summer has been established. However, there is no unified opinion among scientists regarding the interaction between the winter and summer monsoons.

There is a biennial oscillation phenomenon in tropospheric circulation and precipitation, especially in the Asian monsoon region, in addition to the Quasi Biennial Oscillation $(\mathrm{QBO})$ in the stratosphere. This phenomenon is termed the Tropospheric Biennial Oscillation (TBO) [8,9]. Previous research has described the East Asian summer monsoon rainfall pattern as a distinct biennial oscillation feature $[10,11]$. However, the dynamical mechanism of this feature 
is not well understood. It is possible that this process is closely related to the 2-year component of ENSO [12,13]. Indeed, $\mathrm{Li}$ et al. [14] pointed out that the interaction between EAWM and ENSO may be the important mechanism to excite the TBO. In addition, the TBO has been associated with the thermodynamic conditions in the Western Pacific Ocean, especially vapor transportation [15]. Chen et al. [16] studied the mechanism of the TBO from a wider point of view, and suggested that the activity of stationary planet waves would affect the troposphere though the QBO, and then influence variation in the TBO.

In the present study, the entire East Asia monsoon system is analyzed. First, a new unified monsoon index was defined, and its variation was investigated to identify the different life cycles of the East Asian monsoon and the interaction between the summer and winter parts of the East Asian monsoon. Finally, it is suggested that the developing and shifting process of these two monsoon components in East Asia may be the important mechanism to excite the TBO over the East Asian monsoon region.

\section{Data}

The basic dataset employed consists of 40 years (1961$2000)$ of EMWCF daily averaged data archived in 23 pressure levels extending from 1000 to $1 \mathrm{hPa}$. These data had a horizontal resolution of $2.5^{\circ} \times 2.5^{\circ}$. Daily anomalies in the field variables were taken as deviations from daily values of the above 40-year mean. Another dataset used was the 121-year Mei-yu dataset from 1885 to 2005 from the National Climate Center of China Meteorology Administration. This dataset was constructed by averaging the data points at five stations, Shanghai, Nanjing, Wuhu, Jiujiang and Wuhan.

\section{Unified East Asian monsoon index}

In earlier research, both the East Asian summer monsoon (EASM) and the East Asian winter monsoon (EAWM) were regarded as individual study entities. Many different indices have been applied to describe the activity and anomalies of each monsoon separately. Initially, Guo [17] defined an EASM intensity index, which could depict clearly the feature of sea level pressure (SLP) differences over the East Asian and West Pacific Oceans, and could identify the differences between land and ocean to describe the entire EASM process. Later, the South China Sea summer monsoon index was selected to represent the activity of the EASM. Different variables were applied to define this index, such as an $850-\mathrm{hPa}$ wind field, outgoing longwave radiation (OLR) and the departure of the divergence between high and low tropospheric levels [18-20]. Even the zonal wind departure between tropical and subtropical areas or teleconnection wave trains were chosen as EASM indices $[21,22]$. These studies concluded that it was better to apply elements of the wind field than precipitation to define a summer monsoon index in the East Asian monsoon region.

With regard to the EAWM, cold wave events often are used to denote its activity. Shi et al. [23] applied the difference of zonal belt mean SLP from $20^{\circ}$ to $50^{\circ} \mathrm{N}$, between $110^{\circ}$ and $160^{\circ} \mathrm{E}$, to define the EAWM intensity index. Other variables used as indices to describe winter monsoon activity in the East Asian region include a $500-\mathrm{hPa}$ potential height, and temperature and northerly wind components [24]. However, while different variables have been used, the basic features of the EAWM have correlated with each other.

In East Asia, northeasterly winds prevail in winter, while southwesterly winds dominate in summer (Figure 1). Based on these wind conditions, we selected the southwest-northeast wind velocity as the crucial variable. The process involved averaging the domain of grid points lying within the study area $110^{\circ}-122.5^{\circ} \mathrm{E}$ and $10^{\circ}-22.5^{\circ} \mathrm{N}$. Then, the normalized data were calculated as the unified EAMI:

$$
\mathrm{EAMI}=V /\left[\sum(V)^{2} / n\right]^{1 / 2},
$$

where $V$ stands for $\frac{u+v}{\sqrt{2}}, u$ and $v$ are the zonal and meridional winds, respectively, and $n$ is the sample number (the days of the datum). Accordingly, we obtained the daily EAMI.
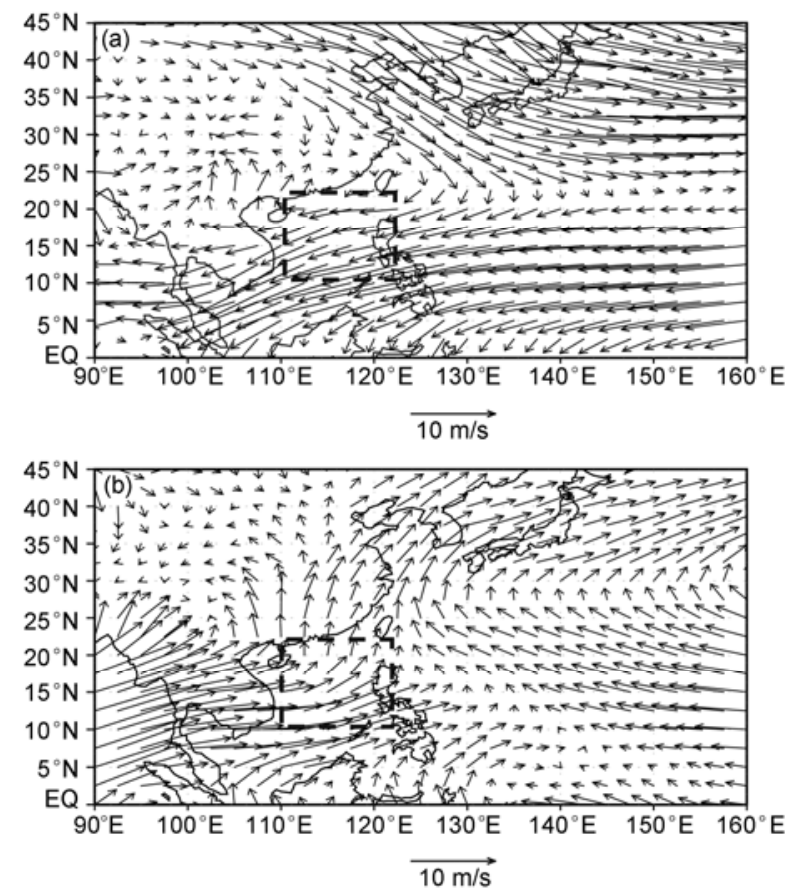

Figure 1 The 850-hPa wind field averaged between 1961-2000 in January (a) and July (b). 
Figure 2 depicts the seasonal variation of daily multiyear mean EAMI data. This index shows clearly the basic circulation characteristics of both summer and winter monsoons. It is applicable not only to winter monsoons, but also to summer monsoons. This index can reflect the transition feature of winter and summer monsoons. In general, the East Asian summer monsoon onsets in late May, and retreats in October. Then, the East winter monsoon is established in mid-October and vanishes in May. Using this simple index, the basic process of the entire cycle of the East Asian monsoon system is presented. In summer, the shift from winter monsoon to summer monsoon is less abrupt than the transition from summer to winter. That is, the contour is less steep in mid-September (shift time from summer to winter), compared with that in May, which is the transition time from winter to summer.

Zeng et al. [25,26] proposed a method to divide the global monsoon region and quantitatively estimate the atmospheric circulation transition time. The index defined in this paper is similar to their estimate.

\section{Relationship between the EAWM and EASM anomaly}

In the present study, we applied a composite analysis method to reveal the relationship between the EASM and EAWM anomaly. We selected a 3-month (December, January, and February) mean EAMI to represent winter conditions, and a 3-month (June, July, and August) mean for summer conditions. Then, summer EAMI values greater than 0.8 were selected as strong summer monsoon cases. We obtained 15 strong summer monsoon cases $(1967,1968$, 1972, 1974, 1975, 1981, 1982, 1984, 1985, 1990, 1991, 1993, 1994, 1997, and 1999) from 40 samples. These 15 cases were composites of strong summer monsoon cases. Then, composite results were subtracted from the multiyears mean EAMI. Finally, the strong summer monsoon

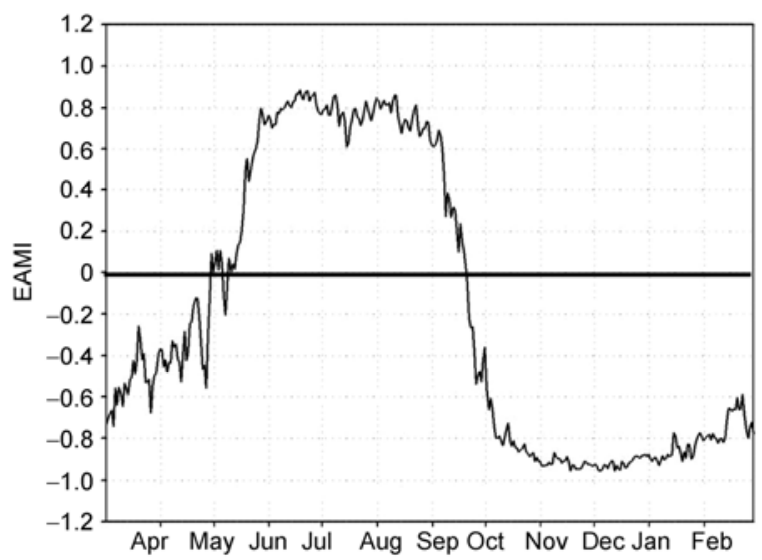

Figure 2 Seasonal variation of a multi-year (1961-2000) mean EAMI (based on a daily datum). anomaly of the EAMI was obtained. The variation of the summer anomaly of the EAMI is shown in Figure 3. With regard to the strong summer EAMI cases, the seasonal variation of the EAMI shows that weak winter monsoons often come after strong summer monsoon events (EAMI appears as a positive anomalous situation). Thus, this index indicates that strong summer monsoons result in weak winter monsoons.

We used the threshold value 0.66 to select weak summer monsoon years (cases where EAMI was less than 0.66). We obtained 11 weak summer cases (1964, 1966, 1969, 1971, 1980, 1983, 1988, 1989, 1995, 1996, and 1998). This method was similar to that for strong summer monsoon cases. We subtracted the multi-year mean EAMI from the composite of weak summer monsoon cases to find the weak summer monsoon anomaly. The results are shown in Figure 4. Strong winter monsoons (negative in EAMI) often follow weak summer monsoon cases, which have negative values of EAMI.

\section{Variation of the East Asian monsoon and TBO}

The analysis in section 4 shows clearly that weak winter monsoon events often follow strong summer monsoon

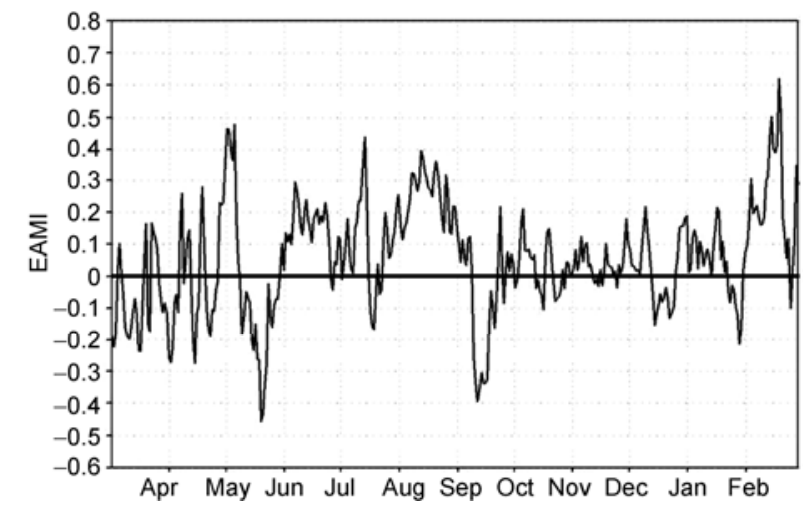

Figure 3 Variation of EAMI anomaly composite of strong summer monsoon cases.

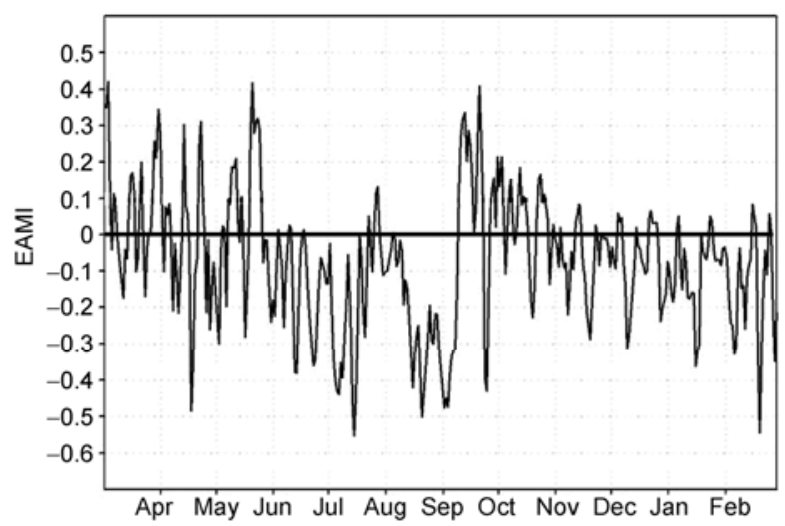

Figure 4 Variation of EAMI anomaly composite of weak summer monsoon cases. 
cases, while strong winter monsoon events follow weak summer monsoon cases. In other words, there is an out-ofphase pattern between summer and the following winter monsoon cases. In this section, we discuss the conditions that relate the following summer monsoon to the preceding anomalous winter monsoon. First, strong cases were selected. Then, the EAMI anomaly was achieved by subtracting the composite result from the climatological mean EAMI. The strong winter monsoon cases included 13 years (1961, 1966, 1969, 1970, 1971, 1973, 1975, 1981, 1985, 1988, 1995,1998 , and 1999). The seasonal variation of the EAMI anomaly in relation to strong winter cases can be seen in Figure 5. After strong winter cases (negative EAMI in winter), the following summer monsoon tends to be strong. That is, the EAMI anomaly is positive in summer. With weak winter monsoon cases, the following summer monsoon is weak (negative EAMI in summer) (figure not shown). In winter monsoon composite cases, the winter monsoon and summer monsoon have an in-phase pattern. Strong (weak) winter monsoons often activate strong (weak) summer monsoons. These results are supported by previous studies [24].

In the East and South Asian monsoon regions, there is a prominent periodic oscillation phenomenon extending from the troposphere to the stratosphere. This phenomenon has a period of about 2 years. In the stratosphere, this kind of oscillation is called the Quasi-Biennial Oscillation (QBO), and in the troposphere, it is called the TBO. We obtained TBO characteristics from the Mei-yu in the Yangtze River valley. Figure 6 presents the wavelet results of the Meiyu in the Yangtze River valley. In addition, there is high variability in Meiyu precipitation. The distinct periods were, respectively, $11,5-8$ and 2 years. Different dynamical mechanisms were used to explain the distinct activity periods. The 11-year oscillation was affected by solar activity [27] and the Pacific Decadal Oscillation (PDO) of SSTA in the North
Pacific [28]. The 5-8 year oscillation was influenced by anomalous atmospheric circulation induced by the ENSO cycle [29]. The 2-year oscillation was associated clearly with some important atmospheric circulation process, especially the anomalous condition of the East Asian summer monsoon. Weak summer monsoon events bring more Mei-yu precipitation, while strong summer monsoon events bring less precipitation in the Yangtze River valley area.

The TBO phenomenon of the Meiyu precipitation in the Yangtze River valley is closely related to the East Asian summer monsoon activity in different aspects $[11,15]$. The static aspects have been evaluated extensively in the literature and are not discussed in this paper. Furthermore, this paper focuses on the compact monsoon cycle that exists between a strong and weak, and a winter and summer, monsoon. The schematic diagram in Figure 7 illustrates this concept.

This monsoon cycle (Figure 7) describes the connection between winter and summer monsoons. It represents a 2-year cycle, which just fits the oscillation period of the TBO. Thus, a strong summer monsoon will induce a weak

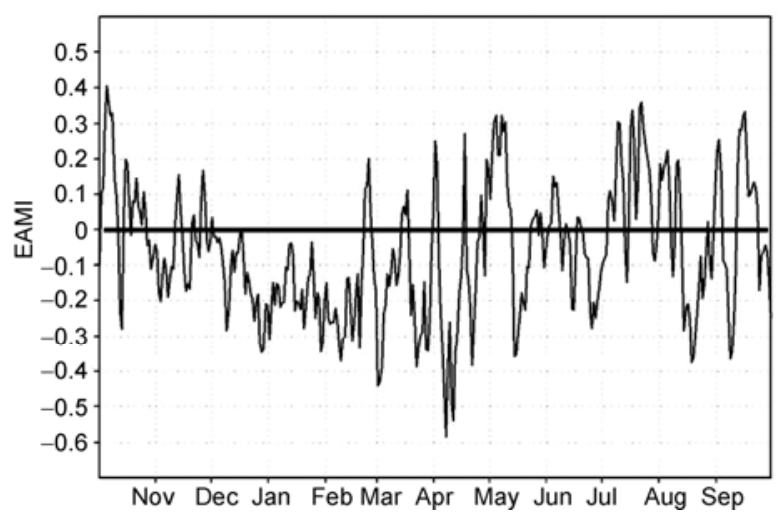

Figure 5 Variation of the EAMI anomaly composite of strong winter monsoon cases.

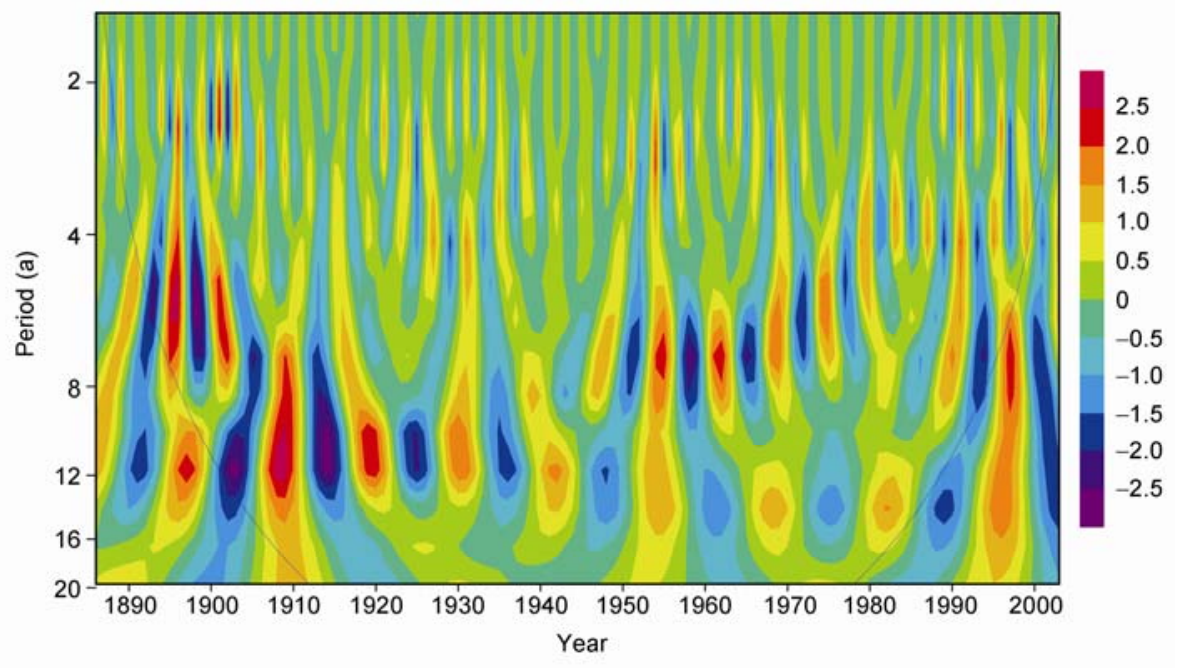

Figure 6 Wavelet results of Meiyu in the Yangtze River valley. 


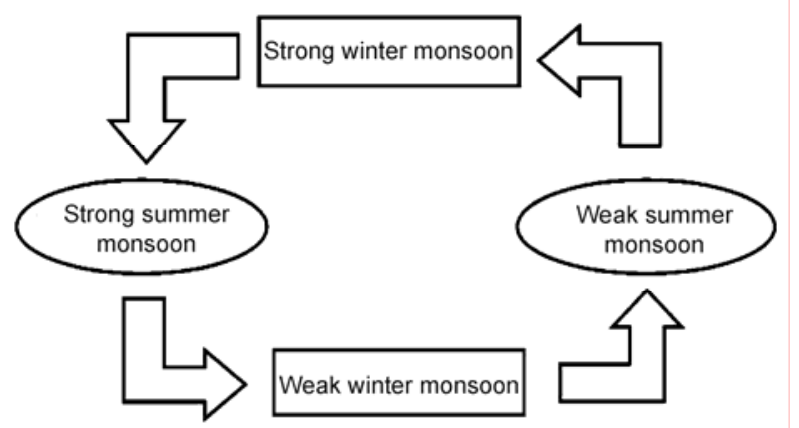

Figure 7 Schematic diagram of anomalous East Asia monsoon interaction cycle.

winter monsoon, and a weak winter monsoon leads to a weak summer monsoon, which is followed by a strong winter monsoon. Thus, the strong winter monsoon usually precedes a strong summer monsoon, which indicates the beginning of the monsoon cycle. The closed relationship between summer monsoons and Meiyu precipitation allows for identification of the East Asian monsoon cycle. In addition, it appears that the interaction between summer and winter monsoons may be an important dynamic mechanism that leads to the TBO.

\section{Discussion and conclusions}

To study and compare the transition features and interactions of winter and summer monsoons, a unified EAMI was defined. This index described not only the characteristics of the winter but also of the summer monsoon. This index also can be used to identify the transition features between winter and summer monsoons. The results are in agreement with the currently existing single summer or winter monsoon indices, and highlight the advantages of a simple unified EAMI.

In the previous section of this paper, the composite method was applied to different anomalous circumstances and the different interactive relationships between winter and summer monsoons. The results showed that strong winter monsoons lead to strong summer monsoons, while weak winter monsoons lead to weak summer monsoons. With summer cases, weak summer monsoons result in strong winter monsoons, while strong summer cases result in strong winter events. On the basis of these general rules, a monsoon cycle can be constructed over a 2-year period, which includes the TBO period.

The TBO is an important oscillation mode of atmospheric circulation in the East Asian region. The compact cycle of monsoons, which describes the interaction process between strong and weak, and winter and summer monsoons, may be an important mechanism to excite the TBO.

The present study focuses on East Asian monsoon activity, and discusses a possible internal mechanism for the
TBO. This internal mechanism does not contradict the external possible TBO mechanism mentioned in section 1, but can be seen as a supplementary explanation to the process. From this study, we achieve further detailed knowledge about the TBO. Further studies may investigate the dynamic mechanism of the atmospheric system based on a combination of internal and external factors.

This work was supported by the National Natural Science Foundation of China (U0833602), and the National Basic Research Program of China (2007CB411805 and 2010CB950400).

1 Chen L X, Zhu Q G, Luo H B, et al. East Asian Monsoon (in Chinese). Beijing: China Meteorological Press, 1991. 362

2 Institute of Atmospheric Physics, Chinese Academy of Sciences. East Asian Monsoon and Torrential Rain in China (in Chinese). Beijing: China Meteorological Press, 1998. 503

3 Chang C P. East Asian Monsoon. Singapore: World Scientific Publisher, 2004. 416

4 Sun S Q, Sun B M. The relationship between the anomalous winter monsoon circulation over East Asia and summer drought/flooding in the Yangtze and Huaihe River valley (in Chinese). Acta Meteorol Sin, 1995, 57: 513-522

5 Chen J, Sun S Q. Eastern Asian winter monsoon anomaly and variation of global circulation, Part I: A comparison study on strong and weak winter monsoon (in Chinese). Chin J Atmos Sci, 1999, 23: 101111

6 Zhao Z G. The Summer Drought/Flooding in China and Its Environment Field (in Chinese). Beijing: China Meteorological Press, 1999. 28-37

7 Chen W, Graf H F, Huang R H. Interannual variability of East Asian winter monsoon and its relation to the summer monsoon. Adv Atmos Sci, 2000, 17: 48-60

8 Meehl G. The annual cycle and interannual variability in the tropical Pacific and Indian Ocean region. Mon Weather Rev, 1987, 115: 2750

9 Ropelewski C F, Halpert M S, Wang X. Observed tropospherical biennial variability and its relationship to the Southern Oscillation. J Clim, 1992, 5: 594-614

10 Miao J H, Lau K M. Interannual variability of East Asian monsoon rainfall. Quart J Appl Meteor, 1990, 1: 377-382

11 Yin B Y, Wang L Y, Huang R H. The Quasi-Biennial oscillation of the East Asian summer monsoon rainfall and its possible mechanism. In: Huang R H, ed. Disastrous Climate (in Chinese). Beijing: China Meteorological Press, 1996. 196-205

12 Lau K M, Shen P J. Annual cycle, quasi-biennial oscillation and Southern Oscillation in global precipitation. J Geophys Res, 1988, 93: 10975-10988

13 Rasmussen E M, Wang X, Ropelewski C F. The biennial component of ENSO variability. J Mar Syst, 1990, 1: 71-90

14 Li C Y, Sun S Q, Mu M Q. Origin of the TBO-Interaction between anomalous East-Asian winter monsoon and ENSO cycle. Adv Atmos Sci, 2001, 18: 554-566

15 Huang R H, Chen J L, Huang G, et al. The Quasi-Biennial oscillation of summer monsoon rainfall in China and its cause (in Chinese). Chin J Atmos Sci, 2006, 30: 545-560

16 Chen W, Li T. Modulation of northern hemisphere wintertime stationary planetary wave activity: East Asian climate relationships by the Quasi-Biennial Oscillation. J Geophys Res, 2007, 112: D20120, doi: 10.1029/2007JD008611

17 Guo Q Y. The summer monsoon intensity index in East Asia and its variation (in Chinese). Acta Geogr Sin, 1983, 3: 207-217

18 Liang J Y, Wu S S, You J P. The research on variations of onset of the SCS summer monsoon and its intensity (in Chinese). J Trop Meteorol, 1999, 15: 97-105 
19 He J H, Zhu Q G, Murakami M. TBB data revealed features of Asian-Australian monsoon seasonal transition and Asian summer monsoon establishment (in Chinese). J Trop Meteorol, 1996, 12: 34-42

20 Li C Y, Zhang L P. The characteristics of South China Sea summer monsoon and its intensity index (in Chinese). Prog Nat Sci, 1999, 9: 536-541

21 Zhang Q Y, Tao S Y, Chen L T. The inter-annual variability of East Asian summer monsoon indices and its association with the pattern of general circulation over East Asia (in Chinese). Acta Meteorol Sin, 2003, 61: 559-568

22 Huang G. Study of the relationship between summer monsoon circulation and anomaly index and the climatic variations in East Asia (in Chinese). Quart J Appl Meteorol, 1999, 10: 61-69

23 Shi N, Zhu Q G, Wu B G. The east Asian summer monsoon in relation to summer large scale weather-climate anomaly in China for the last 40 years (in Chinese). Chin J Atmos Sci, 1996, 20: 575-583
24 Yan H M, Duan W, Xiao Z N. A study on relation between Asian winter monsoon and climatic change during raining season in China (in Chinese). J Trop Meteorol, 2003, 19: 367-376

25 Zeng Q C, Zhang B L. On the seasonal variation of atmospheric general circulation and the monsoon (in Chinese). Chin J Atmos Sci, 1998, 22: 805-813

26 Li J P, Zeng Q C. A new monsoon index and the geographical distribution of the global monsoons. Adv Atoms Sci, 2003, 20: 299-302

27 Pan J, Li C Y, Gu W. The possible impact of solar activity on summer rainfall anomaly in eastern China (in Chinese). Sci Meteorol Sin, 2010, 30: 6-13

28 Li C Y, Xian P. Atmospheric anomalies related to interdecadal variability of SST in the North Pacific. Adv Atmos Sci, 2003, 20: 859-874

29 Zong H F, Zhang Q Y, Chen L T. Temporal and spatial variation of precipitation in eastern China during the Meiyu period and their relationships with circulation and sea surface temperature (in Chinese). Chin J Atmos Sci, 2006, 30: 1189-1197

Open Access This article is distributed under the terms of the Creative Commons Attribution License which permits any use, distribution, and reproduction in any medium, provided the original author(s) and source are credited. 